\title{
What Do Men with Metastatic Prostate Cancer Consider When Making Treatment Decisions? A Mixed-methods Study
}

This article was published in the following Dove Press journal: Patient Preference and Adherence

\author{
Laura B Oswald (D) \\ Frank A Schumacher ${ }^{2}$ \\ Brian D Gonzalez (D) \\ Kelvin A Moses ${ }^{3}$ \\ David F Penson ${ }^{3,4}$ \\ Alicia K Morgans ${ }^{2}$ \\ 'Health Outcomes and Behavior \\ Program, Moffitt Cancer Center, Tampa, \\ FL, USA; ${ }^{2}$ Department of Medicine \\ (Hematology and Oncology), \\ Northwestern University Feinberg \\ School of Medicine, Chicago, IL, USA; \\ ${ }^{3}$ Department of Urology, Vanderbilt \\ University Medical Center, Nashville, TN, \\ USA; ${ }^{4}$ Department of Urology, VA \\ Tennessee Valley Geriatric Research, \\ Education, and Clinical Center (GRECC), \\ Nashville, TN, USA
}

Objective: Metastatic prostate cancer ( $\mathrm{mPCa}$ ) patients often make complicated treatment decisions, yet decision aids to facilitate shared decision-making for $\mathrm{mPCa}$ are uncommon. To inform the development of patient-centered $\mathrm{mPCa}$ decision aids, we examined what $\mathrm{mPCa}$ survivors considered most important when making treatment decisions.

Methods: Using an exploratory sequential approach, we conducted three focus groups with 14 advanced prostate cancer survivors $(n=5, n=3, n=6$ in each group) to identify considerations for making treatment decisions. Focus groups were audio-recorded and transcribed, and we identified qualitative themes. We then developed a quantitative survey to assess the importance of each theme and administered the survey to mPCa survivors $(\mathrm{N}=100)$. We used relative frequencies to determine the most strongly endorsed items and chi-squared and Fisher's exact tests to assess associations with participant characteristics.

Results: Focus groups yielded 11 themes, and the resulting survey included 20 items. The most strongly endorsed $\mathrm{mPCa}$ treatment considerations were: relying on physician's treatment recommendations ( $79 \%$ strongly agree); wanting to feel well enough to spend quality time with loved ones ( $72 \%$ strongly agree); the importance of dying in a manner consistent with one's wishes (70\% strongly agree); hoping to eliminate cancer completely (68\% strongly agree); and optimizing treatment efficacy (65\% strongly agree). Age, race, marital status, employment status, and self-reported health were related to how strongly men endorsed various considerations for $\mathrm{mPCa}$ treatment decision-making.

Conclusion: We identified multiple considerations that $\mathrm{mPCa}$ survivors appraised when making treatment decisions. These data may inform the development of patient-centered decision aids for $\mathrm{mPCa}$.

Keywords: decision-making, focus groups, metastasis, prostate cancer, quality of life
Correspondence: Alicia K Morgans

Northwestern University Feinberg School of Medicine, 676 N. Saint Clair, Suite 850., Chicago, IL 606II, USA

Tel +|3|2-695-238|

Email Alicia.Morgans@northwestern.edu
Prostate cancer (PCa) is the most common cancer among men in the US, accounting for more than $20 \%$ of annual male cancer diagnoses. ${ }^{1}$ Although localized PCa is highly treatable, metastatic PCa $(\mathrm{mPCa})$ is incurable and the second leading cause of cancer death in the US (five-year survival of 31\%,33,330 deaths expected in 2020). ${ }^{1}$ Men with $\mathrm{mPCa}$ face choices between multiple noncurative systemic treatment options with various side effect profiles, financial obligations, and modes of delivery, but all treatments result in similar survival benefits. ${ }^{2}$ There is often not a "best" mPCa treatment option in terms of expected efficacy, and the optimal sequence of treatments to optimize efficacy remains an active area of investigation. $^{3-7}$ 
Due to the complexity of treatment options, professional societies (eg, American Urological Association) recommend shared decision-making as an ideal approach to prostate cancer treatment decisionmaking. ${ }^{8}$ In shared decision-making, patients and providers collaboratively make treatment decisions based on clinical information (ie, available treatments, risks, benefits, costs) and patients' values and preferences. ${ }^{9,10}$ However, shared decision-making is complex, and it can be difficult to accomplish in the limited time available for clinical consultation and care. Thus, decision aids can facilitate shared decision-making by increasing patient knowledge about treatment options. ${ }^{11}$ For prostate cancer, decision aids have largely been studied in the context of localized disease and prostate-specific antigen (PSA) screening.

Decision aids range from basic informational pamphlets to more sophisticated and interactive technology and internet-based tools. Despite considerable variability in the quality of decision aids and their adherence to criteria outlined in the International Patient Decision Aid Standards, ${ }^{12,13}$ decision aids for localized prostate cancer and PSA screening are associated with improved decisional outcomes (eg, reduced decisional conflict and regret, improved knowledge, satisfaction, and perceptions of control). ${ }^{12,14-16}$ However, few empirically supported decision aids have been developed for $\mathrm{mPCa}$, leaving men with $\mathrm{mPCa}$ with little evidence-based guidance for facilitating shared decision-making. This is a significant oversight, particularly as the landscape of $\mathrm{mPCa}$ treatments continues to increase in complexity. Because patients' values and preferences are a critical component of shared decision-making, an important first step in the development of empirically supported patient-centered decision aids is to better understand $\mathrm{mPCa}$ patients' considerations when making treatment decisions.

To address this need, we identified and characterized the considerations that affect how $\mathrm{mPCa}$ patients make treatment decisions using a mixed-methods approach. First, we conducted focus groups to identify treatment decision-making considerations. Then, using the resulting information, we developed and administered a survey to $\mathrm{mPCa}$ survivors to determine which treatment decision-making considerations they most strongly endorsed. Finally, we explored associations between patient characteristics and treatment decision-making considerations.

\section{Methods}

\section{Participants and Procedures}

We performed an exploratory sequential mixed-methods study including an initial qualitative phase of data collection and analysis, followed by a quantitative data collection and analysis phase. This study was approved by the Institutional Review Board at Vanderbilt University Medical Center (VUMC; approval \#140871).

\section{Qualitative Phase: Focus Groups}

From August to September 2014, men with advanced incurable prostate cancer were recruited from urology and medical oncology clinics at VUMC to participate in focus groups $(\mathrm{k}=3)$ as a qualitative exploration of treatment decision-making considerations for men with incurable prostate cancer. All participants provided informed consent, including consent to publish anonymized responses. Focus groups were completed in person and required patients to report to a facility that was distinct from the clinical setting and to come at a time outside of scheduled appointments. To improve feasibility of recruitment and attendance at focus groups, both men with biochemical recurrence and with $\mathrm{mPCa}$ were included in the focus groups if their prostate cancer was considered incurable. A standard moderator's guide was used for each group that included questions about relevant topic areas generated from the literature and clinical experience. Broad topic areas identified a priori were queried related to what is important to men with incurable $\mathrm{PCa}$ as they make treatment decisions for their PCa. These topics were explored to identify specific patient-developed themes, and focus groups were performed until thematic saturation was reached. Focus groups were audio-recorded, transcribed verbatim, de-identified, and analyzed systematically to identify qualitative themes. Initial themes were developed using the first focus group transcript, and themes were added and revised to capture the content of discussions. The coding system was reviewed and revised by the principal investigator AKM, and the final coding system was applied to all three focus group transcripts. Participants also reported sociodemographic and clinical information via a demographics survey.

\section{Quantitative Phase: Survey}

For the quantitative phase of the study, we developed a survey based on the themes identified in the focus groups to determine which of the treatment considerations $\mathrm{mPCa}$ survivors most strongly endorsed as being important to 
them. Items were developed to probe aspects of each theme identified in the qualitative phase of the study. From October 2015 to November 2016, mPCa survivors who had not participated in the focus groups were recruited from urology and medical oncology clinics at VUMC and online from ZEROCancer.com, a nonprofit organization that provides patients and caregivers with prostate cancer education and advocacy activities. The survey component of this study was largely hypothesis generating, thus a recruitment goal of 100 participants was deemed acceptable. After providing informed consent, including consent to publish anonymized responses, participants completed surveys describing their sociodemographic and clinical characteristics and rated their perceived health (ie, "How would you describe your overall health right now?") with the following response options: excellent, good, fair, and poor. Participants rated their agreement with statements about treatment decisionmaking on a Likert-scale from strongly agree (1) to strongly disagree (5). Participants recruited from ZEROCancer.com completed the survey online, whereas participants recruited from VUMC clinics completed the survey in clinic using paper forms. The data that support these findings are available from the corresponding author upon reasonable request.

\section{Data Analysis}

Qualitative data were divided into short quotes containing a single thought or idea and loaded into Microsoft Excel to facilitate coding by two coders. Quantitative data were analyzed using IBM SPSS Statistics for Windows, Version 25.0 (IBM Corporation, Armonk, NY, USA). We used descriptive statistics to characterize the participants. For focus group data, an initial codebook was developed and two independent coders assessed the transcripts for overarching themes. ${ }^{17}$ Disagreements were resolved by consensus. Analysis continued until thematic saturation was reached (ie, the point at which no further themes were identified). ${ }^{18}$

For survey data, we used relative frequencies to determine the most strongly endorsed items (ie, proportion of participants who responded strongly agree). Item responses were dichotomized in this way to allow us to identify the treatment decision-making considerations that participants endorsed most strongly. We used Fisher's exact test to explore associations between participant characteristics and likelihood of strongly endorsing each item (ie, strongly agree vs other response) across the following participant characteristics: age (median split $<68$ vs $\geq 68$ years old), race (non-white vs white), marital status (mar$\mathrm{ried} /$ partnered vs not married/partnered), employment status (working vs retired) and self-reported health (poor/fair vs good/excellent). Significance was determined by $p<0.05$.

\section{Results}

\section{Participant Characteristics}

Table 1 describes the characteristics of the focus group participants $(\mathrm{N}=14$ total across $\mathrm{k}=3$ focus groups) and survey participants $(\mathrm{N}=100)$. Most focus group participants had $\mathrm{mPCa}(79 \%)$ and were median ages of 71,62 , and 72 years old in each of the focus groups, respectively. Participants were primarily white (93\%) and married/partnered (79\%).

Survey participants all had $\mathrm{mPCa}$ and were a median age of 68 years old. Participants were primarily white (88\%), married/partnered (80\%), retired (63\%), and insured (99\%). There were no characteristic differences between participants recruited from VUMC $(n=77)$ and ZEROCancer.com $(n=23)$, with the exception that participants recruited from ZEROCancer.com were more likely to be retired $\left(\chi^{2}(1)=6.02, p=0.01\right)$.

\section{Qualitative Themes of Treatment Decision-making Considerations}

Focus groups yielded 11 themes related to treatment decision-making. Here, we briefly describe the themes and present select representative quotes. Additional quotes are included in the Supplemental Table.

\section{Confidence in Physician's Expertise}

Most participants reported relying on their physician's recommendations for planning their treatment approach. As treatments failed and new treatments were identified, participants relied heavily on their physician to identify next steps.

I just listen to what the doctor says and follow her advice.

I'm content with that.

\section{Eliminating Cancer}

The possibility of completely eliminating cancer was a salient consideration among participants. Despite the cognitive acceptance that advanced prostate cancer is incurable, many participants expressed hope that the next treatment or discovery could result in cure.

I think we are all just hoping for that miracle drug. 
Table I Sociodemographic and Clinical Characteristics of Men Who Participated in the Focus Groups and Survey

\begin{tabular}{|c|c|c|c|c|}
\hline Variables & Focus Group I $(n=5)$ & Focus Group $2(n=3)$ & Focus Group $3(n=6)$ & Survey $(n=100)$ \\
\hline Age, years; median & 71 & 62 & 72 & 68 \\
\hline \multicolumn{5}{|l|}{ Race/ethnicity; n (\%) } \\
\hline White & $5(100)$ & $3(100)$ & $5(83)$ & $88(88)$ \\
\hline Black/African American & 0 & 0 & 0 & $10(10)$ \\
\hline Other & 0 & 0 & I (I7) & $2(2)$ \\
\hline \multicolumn{5}{|l|}{ Marital status; n (\%) } \\
\hline Married or partnered & $5(100)$ & $2(67)$ & $4(67)$ & $80(80)$ \\
\hline Not married or partnered & 0 & I (33) & $2(33)$ & $19(19)$ \\
\hline \multicolumn{5}{|l|}{ Employment status; n (\%) } \\
\hline Working & & & & $35(35)$ \\
\hline Retired & & & & $63(63)$ \\
\hline \multicolumn{5}{|l|}{ Health insurance status; $\mathrm{n}$ (\%) } \\
\hline Insured & & & & $99(99)$ \\
\hline Not insured & & & & $I(I)$ \\
\hline \multicolumn{5}{|l|}{ Self-reported health; n (\%) } \\
\hline Excellent or good & & & & $68(68)$ \\
\hline Fair or poor & & & & $30(30)$ \\
\hline \multicolumn{5}{|l|}{ Disease status; n (\%) } \\
\hline Biomedical recurrence & I (20) & I (33) & I (I7) & 0 \\
\hline Metastatic & $4(80)$ & $2(67)$ & $5(83)$ & $100(100)$ \\
\hline Most recent PSA, ng/mL; M (SD) & & & & $12.33(23.66)$ \\
\hline \multicolumn{5}{|l|}{ Site of metastasis; n (\%) } \\
\hline Bone & & & & $79(79)$ \\
\hline Lymph node & & & & $27(27)$ \\
\hline Liver & & & & $2(2)$ \\
\hline Lung & & & & $3(3)$ \\
\hline Other & & & & $3(3)$ \\
\hline Do not know & & & & $7(7)$ \\
\hline \multicolumn{5}{|l|}{ Total number of metastases; $n(\%)$} \\
\hline I & & & & $77(77)$ \\
\hline 2 & & & & II (II) \\
\hline 3 & & & & $5(5)$ \\
\hline Do not know & & & & $7(7)$ \\
\hline
\end{tabular}

Notes: Only brief sociodemographic information was collected from focus group participants. Among survey participants, variables with missing data are age ( $\mathrm{n}=96$ ), marital status $(n=99)$, employment status $(n=98)$, self-reported health $(n=98)$, and most recent PSA $(n=97)$.

Abbreviations: M, mean; PSA, prostate-specific antigen.

\section{Prolonging Survival}

Participants prioritized treatments that would help them prolong survival. For many, family and marital relationships influenced this factor.

My wife says, "Just do what you can to stick around."

\section{Quality of Life (QOL)}

Many participants felt that prolonging survival must be balanced with QOL, defined as continuing to live in a reasonably normal way, carrying on basic activities of daily living, and maintaining quality interpersonal relationships.

Some participants expressed a high value of QOL, whereas others were willing to sacrifice QOL for longer survival.

For me it's really a pretty easy decision. I'm willing to live in discomfort. I'll do whatever.

I would go for the quality of life over the quantity over life, I think every time. 


\section{Side Effects}

Participants described many treatment side effects including memory loss, trouble thinking, pain, bruising, fatigue, erectile dysfunction, and loss of libido. They discussed how side effects can interfere with daily activities, including work and hobbies. While participants were aware of potential treatment-related side effects, they often chose treatments to prolong survival or suppress the cancer despite these side effects.

Chemo has pretty serious side effects of its own, so you know there's that trade off all the time.

\section{Pain Relief}

Pain is a common and intractable side effect of advanced prostate cancer, and pain relief was identified as a significant consideration. Some participants reported willingness to use powerful narcotics to manage cancerrelated pain. Other participants expressed unwillingness to undergo further surgery because of the anticipated pain and potential disability.

Radiation won't cure [the cancer] but it will relieve the pain.

\section{Treatment Efficacy}

Optimizing treatment efficacy is a concern when treating advanced prostate cancer. Several participants discussed the importance of optimal sequencing of treatments, so as not to eliminate future treatment options. Others commented that having prostate cancer creates complications for treating other, unrelated health issues.

If I had gone on that drug trial, then I wouldn't have been able to do the second.

\section{Financial Toxicity}

Although paying for treatment was often not the primary concern, participants considered the cost of treatments and whether treatments would be covered by insurance. Participants voiced complaints about high out-of-pocket costs, insurance companies refusing to cover treatments, and delays in treatment due to extended insurance review.

[The insurance company] called me and said, "You're approved." Then they called back saying, "Well, the good news is that you are approved, but it's going to cost you $\$ 10,000$." I said, “That's not good news."

\section{Treatment Accessibility/Convenience}

For some, having to travel for treatment was a barrier to care. They described the burden of some treatments being unavailable in their local area. Although this was not a primary obstacle for most participants, it was discussed by some as a consideration for how they determined next steps.

They don't have [that treatment option] around here, so you're gone for 6 months ... [if you decide to pursue that treatment].

\section{Fastest Treatment}

Many participants described a sense of time urgency and considered the ability to be treated quickly of high importance. In practice, this can affect treatment choices requiring prior authorization (eg, infusion treatments) or complicated treatment planning requiring multiple specialties (eg, radiopharmaceuticals, immunotherapy). This can also be a barrier for patients who must apply for financial assistance to offset costs of care (eg, via co-payment relief funding sources).

The idea in the beginning was that I had to [get treated] right now. I've got to do everything today.

\section{Decision Regret}

Some participants felt they had made the best treatment choices they could, whereas others expressed regrets and wished they had chosen a different initial treatment approach.

[Looking back] we should've said "No, we're not doing this [treatment]."

\section{Survey Analysis of Treatment Decision-making Considerations}

We developed a 20-item survey to assess treatment decision-making considerations based on the 11 qualitative themes. Table 2 shows the proportion of participants who responded "strongly agree" to each item. The largest proportion of participants strongly endorsed items reflecting reliance on their doctor for making treatment decisions (79\% strongly agree), wanting to feel well enough to spend quality time with loved ones is $(72 \%$ strongly agree), the importance of dying in a manner consistent with one's wishes (70\% strongly agree), hoping to eliminate cancer completely (68\% strongly agree), and treatment sequencing to maintain future treatment options (65\% strongly agree). By contrast, the smallest proportion of participants strongly endorsed items reflecting less time urgency $(20 \%$ strongly agree) and pain relief $(25 \%$ strongly agree). 
Table 2 Proportion of Participants Who Strongly Agreed with Statements About Treatment Decision-making Considerations

\begin{tabular}{|c|c|c|}
\hline $\begin{array}{l}\text { Treatment Decision- } \\
\text { making Consideration }\end{array}$ & Survey Item & $\begin{array}{l}\text { Percent of Participants } \\
\text { Responding “Strongly Agree" }\end{array}$ \\
\hline \multicolumn{3}{|c|}{ Confidence in physician's expertise } \\
\hline & - I rely on my doctor to tell me how to treat my prostate cancer. & 79 \\
\hline \multicolumn{3}{|l|}{ Eliminating cancer } \\
\hline & $\begin{array}{l}\text { - When I choose a cancer treatment, I am hoping for one that will eliminate } \\
\text { the cancer completely. }\end{array}$ & 68 \\
\hline \multicolumn{3}{|l|}{ Prolonging survival } \\
\hline & - Above all, living as long as I can is my most important goal. & 53 \\
\hline & $\begin{array}{l}\text { - I need to live as long as possible, no matter how I feel, so I can continue to } \\
\text { take care of my loved ones. }\end{array}$ & 32 \\
\hline \multicolumn{3}{|l|}{ Quality of life } \\
\hline & $\begin{array}{l}\text { - I am more interested in having a good quality of life rather than the longest } \\
\text { life possible. }\end{array}$ & 59 \\
\hline & $\begin{array}{l}\text { - If I am going to die from cancer, the most important thing for me is to die } \\
\text { with dignity. }\end{array}$ & 70 \\
\hline & $\begin{array}{l}\text { - It is very important to me that I do not end my life so sick I am stuck in } \\
\text { bed. }\end{array}$ & 63 \\
\hline & $\begin{array}{l}\text { - I want a treatment that lets me keep working or doing the things I enjoy } \\
\text { even if it means I will not live as long. }\end{array}$ & 51 \\
\hline & $\begin{array}{l}\text { - Feeling well enough to spend as much quality time as possible with my } \\
\text { loved ones is the most important thing. }\end{array}$ & 72 \\
\hline & - I would choose to die sooner rather than be a burden to my loved ones. & 52 \\
\hline \multicolumn{3}{|l|}{ Side effects } \\
\hline & $\begin{array}{l}\text { - I am willing to put up with uncomfortable side effects as long as the } \\
\text { treatment is slowing the growth of my cancer. }\end{array}$ & 39 \\
\hline & $\begin{array}{l}\text { - I would put up with severe side effects to avoid needing to be in } \\
\text { a wheelchair. }\end{array}$ & 34 \\
\hline & $\begin{array}{l}\text { - I would put up with severe side effects to make sure I have time to } \\
\text { organize my affairs for my loved ones. }\end{array}$ & 56 \\
\hline \multicolumn{3}{|l|}{ Pain relief } \\
\hline & - The most important thing is finding a treatment that minimizes pain. & 25 \\
\hline \multicolumn{3}{|l|}{ Treatment efficacy } \\
\hline & $\begin{array}{l}\text { - I try to choose treatments that will not close any doors to future } \\
\text { treatments. }\end{array}$ & 65 \\
\hline \multicolumn{3}{|l|}{ Financial toxicity } \\
\hline & $\begin{array}{l}\text { - Avoiding financial trouble due to treatment of my prostate cancer is very } \\
\text { important to me. }\end{array}$ & 54 \\
\hline
\end{tabular}


Table 2 (Continued).

\begin{tabular}{|c|c|c|}
\hline $\begin{array}{l}\text { Treatment Decision- } \\
\text { making Consideration }\end{array}$ & Survey Item & $\begin{array}{l}\text { Percent of Participants } \\
\text { Responding "Strongly Agree" }\end{array}$ \\
\hline \multicolumn{3}{|l|}{ Treatment accessibility } \\
\hline & - I am willing to travel as far as necessary to get the best treatment. & 53 \\
\hline \multicolumn{3}{|l|}{ Fastest treatment } \\
\hline & $\begin{array}{l}\text { - I am not in a hurry to treat my cancer, I would rather take my time and } \\
\text { make the best choices. }\end{array}$ & 39 \\
\hline & $\begin{array}{l}\text { - I would choose a treatment that is available now rather than wait for } \\
\text { a treatment that might work better, but requires waiting. }\end{array}$ & 20 \\
\hline \multicolumn{3}{|l|}{ Decision regret } \\
\hline & - I choose my treatment so I will not look back with regret. & 62 \\
\hline
\end{tabular}

Exploratory Fisher's exact test revealed associations between participant characteristics and the likelihood of strongly endorsing individual survey items (Table 3).

\section{Age}

Relative to younger participants, a larger proportion of older participants strongly endorsed the importance of dying with in a manner consistent with one's wishes $(56 \%$ vs $78 \%$, respectively; $\mathrm{OR}=2.80,95 \% \mathrm{CI}: 1.15-6.82, p=0.027)$ and valuing QOL over prolonging survival (32\% vs $58 \%$, respectively; $\mathrm{OR}=3.00,95 \% \mathrm{CI}: 1.28-3.00, p=0.013$ ). In addition, relative to younger participants, a marginally larger proportion of older participants strongly endorsed the importance of avoiding financial toxicity ( $42 \%$ vs $62 \%$, respectively; $\mathrm{OR}=2.29,95 \% \mathrm{CI}: 1.00-5.22, p=0.063$ ).

\section{Race}

Relative to white participants, a larger proportion of nonwhite participants strongly endorsed the importance of prolonging survival to care for loved ones ( $26 \%$ vs $75 \%$, respectively; $\mathrm{OR}=0.12,95 \% \mathrm{CI}: 0.03-0.47, p=0.001$ ), and a marginally larger proportion of non-white participants strongly endorsed the importance of minimizing pain ( $22 \%$ vs $50 \%$, respectively; OR $=0.28,95 \%$ CI: $0.08-0.95$, $p=0.068)$.

\section{Marital Status}

Relative to married/partnered participants, a larger proportion of single participants strongly endorsed willingness to endure severe side effects to avoid needing a wheelchair ( $29 \%$ vs $55 \%$, respectively; OR $=0.33,95 \%$ CI: $0.12-0.90$, $p=0.036$ ), and a marginally smaller proportion of single participants strongly endorsed the importance of feeling well enough to spend quality time with loved ones $(76 \%$ vs $55 \%$, respectively; $\mathrm{OR}=2.63,95 \%$ CI: $0.95-7.29$, $p=0.092$ ).

\section{Employment Status}

Relative to retired participants, a marginally larger proportion of working participants strongly endorsed hope for eliminating cancer completely ( $62 \%$ vs $80 \%$, respectively; $\mathrm{OR}=2.50,95 \%$ CI: $0.95-6.58, p=0.074)$.

\section{Self-reported Health}

Relative to participants with self-reported good/excellent health, a larger proportion of participants with selfreported poor/fair health strongly endorsed hope for eliminating cancer completely ( $43 \%$ vs $78 \%$, respectively; $\mathrm{OR}=0.22,95 \% \mathrm{CI}: 0.09-0.54, p=0.001$ ), willingness to endure uncomfortable side effects to slow cancer growth ( $37 \%$ vs $63 \%$, respectively; OR $=0.34,95 \%$ CI: $0.14-0.82$, $p=0.017$ ), and willingness to endure severe side effects to avoid needing a wheelchair (17\% vs $41 \%$, respectively; $\mathrm{OR}=0.29,95 \%$ CI: $0.10-0.84, p=0.021)$. Moreover, relative to participants with self-reported good/excellent health, a marginally larger proportion of participants with self-reported poor/fair health strongly endorsed the importance of sequencing cancer treatments $(50 \%$ vs $71 \%$, respectively; $\mathrm{OR}=0.47,95 \% \mathrm{CI}: 0.17-1.01, p=0.067)$ and avoiding decision regret $(47 \%$ vs $68 \%$, respectively; $\mathrm{OR}=0.42,95 \%$ CI: $0.17-1.01, p=0.071)$.

\section{Discussion}

In this hypothesis-generating study, we identified what advanced prostate cancer survivors considered when 
Table 3 P-values Indicating the Significance of Fisher's Exact Test Assessing the Relationships Between Participants' Sociodemographic Characteristics and Likelihood of Strongly Endorsing Each Survey Item

\begin{tabular}{|c|c|c|c|c|c|}
\hline Survey Item & Age & Race & $\begin{array}{l}\text { Marital } \\
\text { Status }\end{array}$ & $\begin{array}{l}\text { Employment } \\
\text { Status }\end{array}$ & $\begin{array}{l}\text { Health } \\
\text { Status }\end{array}$ \\
\hline I rely on my doctor to tell me how to treat my prostate cancer & 1.000 & 0.712 & 0.356 & 0.799 & 0.431 \\
\hline $\begin{array}{l}\text { When I choose a cancer treatment, I am hoping for one that will eliminate the } \\
\text { cancer completely }\end{array}$ & 1.000 & 0.747 & 0.285 & $0.074 *$ & $0.001^{* * *}$ \\
\hline Above all, living as long as I can is my most important goal & 0.540 & 0.130 & 0.317 & 0.675 & 0.279 \\
\hline $\begin{array}{l}\text { I need to live as long as possible, no matter how I feel, so I can continue to take } \\
\text { care of my loved ones }\end{array}$ & 0.272 & $0.001 * * *$ & 1.000 & 0.823 & 0.489 \\
\hline $\begin{array}{l}\text { I am more interested in having a good quality of life rather than the longest life } \\
\text { possible }\end{array}$ & $0.013^{* *}$ & 0.760 & 1.000 & 0.213 & 0.118 \\
\hline $\begin{array}{l}\text { If I am going to die from cancer, the most important thing for me is to die with } \\
\text { dignity }\end{array}$ & $0.027^{* *}$ & 0.749 & 0.287 & 0.117 & 0.477 \\
\hline It is very important to me that I do not end my life so sick I am stuck in bed & 0.292 & 1.000 & 0.445 & 0.393 & 1.000 \\
\hline $\begin{array}{l}\text { I want a treatment that lets me keep working or doing the things I enjoy even if it } \\
\text { means I will not live as long }\end{array}$ & 0.675 & 0.543 & 0.617 & 0.671 & 0.825 \\
\hline $\begin{array}{l}\text { Feeling well enough to spend as much quality time as possible with my loved ones } \\
\text { is the most important thing }\end{array}$ & 0.656 & 1.000 & $0.092^{*}$ & 0.817 & 0.628 \\
\hline I would choose to die sooner rather than be a burden to my loved ones & 0.303 & 0.223 & 0.132 & 1.000 & 0.827 \\
\hline $\begin{array}{l}\text { I am willing to put up with uncomfortable side effects as long as the treatment is } \\
\text { slowing the growth of my cancer }\end{array}$ & 0.683 & 0.219 & 0.210 & 1.000 & $0.017^{* *}$ \\
\hline I would put up with severe side effects to avoid needing to be in a wheelchair & 1.000 & 0.329 & $0.036 * *$ & 1.000 & $0.021^{* *}$ \\
\hline $\begin{array}{l}\text { I would put up with severe side effects to make sure I have time to organize my } \\
\text { affairs for my loved ones }\end{array}$ & 0.834 & 0.530 & 1.000 & 0.198 & 0.120 \\
\hline The most important thing is finding a treatment that minimizes pain & 0.345 & $0.068^{*}$ & 0.576 & 0.473 & 0.801 \\
\hline I try to choose treatments that will not close any doors to future treatments & 0.515 & 0.533 & 0.794 & 0.512 & $0.067^{*}$ \\
\hline $\begin{array}{l}\text { Avoiding financial trouble due to treatment of my prostate cancer is very } \\
\text { important to me }\end{array}$ & $0.063^{*}$ & 0.137 & 0.803 & 0.293 & 0.666 \\
\hline I am willing to travel as far as necessary to get the best treatment & 0.148 & 0.368 & 0.618 & 0.675 & 0.129 \\
\hline $\begin{array}{l}\text { I am not in a hurry to treat my cancer, I would rather take my time and make the } \\
\text { best choices }\end{array}$ & 0.217 & 1.000 & 0.114 & 1.000 & 0.108 \\
\hline $\begin{array}{l}\text { I would choose a treatment that is available now rather than wait for a treatment } \\
\text { that might work better, but requires waiting }\end{array}$ & 0.201 & 1.000 & 0.127 & 0.832 & 0.268 \\
\hline I choose my treatment so I will not look back with regret & 1.000 & 0.527 & 0.607 & 1.000 & $0.07 I^{*}$ \\
\hline
\end{tabular}

Notes: Sociodemographic variables were dichotomized as follows: age, median split $<68$ vs $\geq 68$ years old; race, nonwhite vs white; marital status, married/partnered vs not married/partnered; employment status, working vs retired; self-reported health, poor/fair vs good/excellent. $*_{p}<0.10, * * p<0.05, * * * p<0.01$.

making treatment decisions, and we investigated the relative importance of treatment considerations among $\mathrm{mPCa}$ survivors. The three most strongly endorsed treatment decision-making considerations were related to relying on the physician's recommendations and maintaining QOL (ie, to spend time with loved ones and dying in a manner consistent with one's wishes). Many participants also strongly endorsed the importance of treatment efficacy (ie, treatment sequencing), but this was only the fifth most strongly endorsed consideration. Subgroup analyses showed that $\mathrm{mPCa}$ survivors may have different priorities when making treatment decisions depending on demographic characteristics. For example, a larger proportion of older mPCa survivors strongly endorsed survey items related to maintaining QOL and dying with in a manner consistent with one's wishes than younger $\mathrm{mPCa}$ survivors, whereas a larger proportion of non-white $\mathrm{mPCa}$ survivors strongly endorsed wanting to prolong survival to care for loved ones than white mPCa survivors. These findings highlight the importance of tailoring discussions about mPCa treatment decision-making to individual patient characteristics and values.

Our findings are mostly aligned with past studies of treatment considerations for prostate cancer. One study in localized prostate cancer found that patients considered whether potential treatments could eliminate their cancer, extend their survival, delay disease progression, and preserve their QOL in the context of treatment side effects. ${ }^{19}$ 
We identified many similar treatment considerations among men with $\mathrm{mPCa}$, highlighting significant overlap in what patients consider while making treatment decisions for prostate cancer across the disease continuum.

Similar to a study in localized prostate cancer ${ }^{19}$ and a study of patients with advanced prostate cancer, ${ }^{20}$ we found that most patients relied heavily on their physician's recommendations. However, another study in localized disease found that patients relied more on the stories and experiences of others, particularly men who have been previously treated for localized prostate cancer. ${ }^{21}$ It is possible that as prostate cancer progresses to advanced disease, men may have fewer acquaintances with similar disease histories and experiences, making acquaintances less helpful for informing treatment decision-making. Thus, patients may increasingly rely on their physician's expertise as prostate cancer progresses to advanced disease. Men with $\mathrm{mPCa}$ could benefit from programs that provide opportunities for peer support, such as groupbased psychosocial and educational interventions. ${ }^{22}$ Group-based programs such as these inherently increase opportunities to learn from the experiences of other men with $\mathrm{mPCa}$. In addition, when designing decision aids for $\mathrm{mPCa}$, researchers should carefully consider the role of patient narratives. ${ }^{23,24}$ Notably, past work has shown that in clinical practice, the treatment that men receive for localized prostate cancer is more aligned with physician recommendations than with patient preferences. ${ }^{25}$ It is unclear whether this finding generalizes to men with $\mathrm{mPCa}$. Nevertheless, participants in our study of $\mathrm{mPCa}$ clearly described the factors they consider when making treatment decisions, with priorities differing by key sociodemographic characteristics. Future studies should explore strategies for ensuring that patient preferences are not lost in the treatment decision-making process.

We found that financial toxicity, or problems related to the out-of-pocket costs of treatment (eg, co-payments, deductibles, co-insurance), ${ }^{26}$ was not a major consideration for $\mathrm{mPCa}$ treatment decision-making. This is in contrast with recent assessments of decision-making in advanced prostate cancer, in which patients were not willing to accept significant out-of-pocket expenses for treatments. ${ }^{27}$ Our sample was mostly retired and adequately insured, which could influence our results. The experience of financial toxicity likely varies by health literacy, socioeconomic status, and other factors, and the influence of financial toxicity warrants further investigation among mPCa survivors. ${ }^{28}$
Finally, a recent discrete choice experiment of prostate cancer patients and oncologists identified that treatment efficacy and pain control were similarly important when considering treatment choices. ${ }^{29}$ In our study, treatment efficacy emerged as more important than pain control for $\mathrm{mPCa}$ survivors, with treatment efficacy identified as the fifth most strongly endorsed consideration. This underscores the importance of treatment efficacy and sequencing among $\mathrm{mPCa}$ patients.

\section{Study Limitations}

Our sample sizes were small, and there was little socioeconomic diversity in our focus group and survey participants. Most participants were between 60 and 75 years old, white, married, retired, and insured, which may limit the generalizability of our findings to younger men, racial/ethnic minorities, and men who continue to work through cancer treatment. In particular, our finding that financial toxicity did not play a large role in treatment decision-making for $\mathrm{mPCa}$ could be due to the characteristics of our sample and may not reflect the values of the broader population of $\mathrm{mPCa}$ survivors. We did not include caregivers, partners, or other loved ones in our analyses; inclusion of these important cancer care partners in future studies may enhance our understanding of treatment considerations, as spouses are frequently involved in the process of treatment planning. ${ }^{30-33}$ Finally, this study was cross-sectional and we could not assess potential variations in how treatment considerations change over time. Longitudinal studies of treatment decisionmaking considerations for $\mathrm{mPCa}$ will be a valuable addition to this field.

\section{Clinical Implications}

Understanding what men with $\mathrm{mPCa}$ consider when making treatment decisions can inform how clinicians approach challenging conversations about treatment options in practice. $\mathrm{mPCa}$ survivors clearly endorsed the importance of their relationship and trust in their physician, and open communication about patients' values are important for optimizing the doctor-patient relationship. ${ }^{34}$ Studies should continue to elucidate strategies to enable patients to participate in the decision-making process and communicate their treatment considerations and preferences. This may ultimately improve the quality of treatment decisions and outcomes for mPCa. ${ }^{20,30,35}$ 


\section{Conclusions}

We identified multiple considerations that men with $\mathrm{mPCa}$ report are important for treatment decision-making. Several aspects of QOL were consistently identified, including feeling well enough to spend time with loved ones and dying in a manner consistent with one's wishes. These values should be considered as critical components of any treatment decision for this population. Efforts to understand aspects of treatment decisions in more diverse populations remain necessary and are ongoing.

\section{Acknowledgments}

This study was supported by AHRQ K12HS022990 and NCATS CTSA UL1 TR002243. The contents of this manuscript are solely the responsibility of the authors and do not necessarily represent official views of the AHRQ, NCATS, or the NIH.

\section{Disclosure}

Dr Brian D Gonzalez reports personal fees from SureMed Compliance, personal fees from Elly Health, Inc., outside the submitted work. Dr Kelvin Moses reports personal fees from Astellas, personal fees from Pfizer, personal fees from Dendreon, during the conduct of the study. The other authors report no conflicts of interest in this work.

\section{References}

1. American Cancer Society. Cancer Facts \& Figures 2020. Atlanta: American Cancer Society; 2020.

2. Litwin MS, Tan HJ. The diagnosis and treatment of prostate cancer: a review. JAMA. 2017;317(24):2532-2542. doi:10.1001/jama.2017.7248

3. Handy CE, Antonarakis ES. Sequencing treatment for castration-resistant prostate cancer. Curr Treat Option Oncol. 2016;17(12):64

4. Starosta SB, Savage SJ. Castration-resistant prostate cancer: sequencing oral and infusion agents. Curr Urol Rep. 2018;19(9). doi:10.1007/ s11934-018-0826-8

5. Sumanasuriya S, De Bono J. Treatment of advanced prostate cancer-a review of current therapies and future promise. Cold Spring Harb Perspect Med. 2018;8(6). doi:10.1101/cshperspect.a030635

6. Gourdin T. Optimization of therapies for men with advanced prostate cancer: a review of recent developments with a look toward the future. Curr Opin Oncol. 2019;31(3):188-193. doi:10.1097/CCO.00000000 00000521

7. Caffo O, Maines F, Kinspergher S, Veccia A, Messina C. Sequencing strategies in the new treatment landscape of prostate cancer. Future Oncol. 2019;15(25):2967-2982. doi:10.2217/fon-2019-0190

8. American Urological Association. AUA white paper on implementation of shared decision making into urological practice 2015 Available from: https://www.auanet.org/guidelines/shared-decision-making. Accessed September 10, 2020.

9. Kane HL, Halpern MT, Squiers LB, Treiman KA, McCormack LA. Implementing and evaluating shared decision making in oncology practice. CA Cancer J Clin. 2014;64(6):377-388. doi:10.3322/ caac. 21245
10. Hoffmann TC, Legare F, Simmons MB, et al. Shared decision making: what do clinicians need to know and why should they bother? Med J Aust. 2014;201(1):35-39. doi:10.5694/mja14.00002

11. Stacey D, Legare F, Col NF, et al. Decision aids for people facing health treatment or screening decisions. Cochrane Database Syst Rev. 2014;1:CD001431.

12. Vromans RD, van Eenbergen MC, Pauws SC, et al. Communicative aspects of decision aids for localized prostate cancer treatment a systematic review. Urol Oncol. 2019;37(7):409-429.

13. Rooney MK, Morgans AK, Chen RC, et al. Educational material on prostate cancer screening is overly complex and fails to meet recommended layperson readability guidelines. Urology. 2020;135:1-3. doi:10.1016/j.urology.2019.10.006

14. Violette PD, Agoritsas T, Alexander P, et al. Decision aids for localized prostate cancer treatment choice: systematic review and meta-analysis. CA Cancer J Clin. 2015;65(3):239-251. doi:10.3322/ caac. 21272

15. Adsul P, Wray R, Spradling K, Darwish O, Weaver N, Siddiqui S. Systematic review of decision aids for newly diagnosed patients with prostate cancer making treatment decisions. J Urol. 2015;194 (5): $1247-1252$.

16. Zhong W, Smith B, Haghighi K, Mancuso P. Systematic review of decision aids for the management of men with localized prostate cancer. Urology. 2018;114:1-7. doi:10.1016/j.urology.20 17.10 .022

17. NIH Office of Behavioral and Social Sciences. Best Practices for Mixed Methods Research in the Health Sciences. 2nd ed. Bethesda: National Institutes of Health; 2018.

18. Guest G, Namey E, McKenna K. How many focus groups are enough? Building an evidence base for nonprobability sample sizes. Field Method. 2017;29(1):3-22. doi:10.1177/1525822X16 639015

19. Zeliadt SB, Ramsey SD, Penson DF, et al. Why do men choose one treatment over another?: a review of patient decision making for localized prostate cancer. Cancer. 2006;106(9):1865-1874. doi:10. 1002/cner.21822

20. Jones RA, Hollen PJ, Wenzel J, et al. Understanding advanced prostate cancer decision making utilizing an interactive decision aid. Cancer Nurs. 2018;41(1):2-10. doi:10.1097/NCC.00000000000 00442

21. Berry DL, Ellis WJ, Woods NF, Schwien C, Mullen KH, Yang C. Treatment decision-making by men with localized prostate cancer: the influence of personal factors. Urol Oncol. 2003;21(2):93-100. doi:10.1016/S1078-1439(02)00209-0

22. Penedo FJ, Fox RS, Oswald LB, et al. Technology-based psychosocial intervention to improve quality of life and reduce symptom burden in men with advanced prostate cancer: results from a randomized controlled trial. Int J Behav Med. 2020. doi:10.1007/ s12529-019-09839-7

23. Shaffer VA, Zikmund-Fisher BJ. All stories are not alike: a purpose-, content-, and valence-based taxonomy of patient narratives in decision aids. Med Decis Making. 2013;33(1):4-13. doi:10.1177/ 0272989X12463266

24. Shaffer VA, Focella ES, Hathaway A, Scherer LD, Zikmund-Fisher BJ. On the usefulness of narratives: an interdisciplinary review and theoretical model. Ann Behav Med. 2018;52(5):429-442. doi:10. 1093/abm/kax008

25. Scherr KA, Fagerlin A, Hofer T, et al. Physician recommendations trump patient preferences in prostate cancer treatment decisions. Med Decis Making. 2017;37(1):56-69. doi:10.1177/0272989X16662841

26. Zafar SY. Financial toxicity of cancer care: it's time to intervene. J Natl Cancer Inst. 2016;108(5): djv370

27. Benidir T, Hersey K, Finelli A, et al. Understanding how prostate cancer patients value the current treatment options for metastatic castration resistant prostate cancer. Urol Oncol-Semin Ori. 2018;36 (5): $240-\mathrm{e} 13$. 
28. Pisu M, Kenzik KM, Oster RA, et al. Economic hardship of minority and non-minority cancer survivors 1 year after diagnosis: another long-term effect of cancer? Cancer. 2015;121(8):1257-1264. doi:10.1002/cncr.29206

29. de Freitas HM, Ito T, Hadi M, et al. Patient preferences for metastatic hormone-sensitive prostate cancer treatments: a discrete choice experiment among men in three European countries. Adv Ther. 2019;36(2):318-332. doi:10.1007/s12325-018-0861-3

30. Davison BJ, Gleave ME, Goldenberg SL, Degner LF, Hoffart D, Berkowitz J. Assessing information and decision preferences of men with prostate cancer and their partners. Cancer Nurs. 2002;25 (1):42-49. doi:10.1097/00002820-200202000-00009

31. Heyman EN, Rosner TT. Prostate cancer: an intimate view from patients and wives. Urol Nurs. 1996;16(2):37-44.
32. O'Rourke ME, Germino BB. Prostate cancer treatment decisions: a focus group exploration. Oncol Nurs Forum. 1998;25(1):97-104.

33. Srirangam SJ, Pearson E, Grose C, Brown SC, Collins GN, O'Reilly PH. Partner's influence on patient preference for treatment in early prostate cancer. BJU Int. 2003;92(4):365-369. doi:10.1046/ j.1464-410X.2003.04355.x

34. Adamson M, Choi K, Notaro S, Cotoc C. The doctor-patient relationship and information-seeking behavior: four orientations to cancer communication. J Palliat Care. 2018;33(2):79-87. doi:10.1177/ 0825859718759881

35. Clark JA, Wray NP, Ashton CM. Living with treatment decisions: regrets and quality of life among men treated for metastatic prostate cancer. J Clin Oncol. 2001;19(1):72-80. doi:10.1200/JCO.2001. 19.1.72
Patient Preference and Adherence

\section{Publish your work in this journal}

Patient Preference and Adherence is an international, peer-reviewed, open access journal that focusing on the growing importance of patient preference and adherence throughout the therapeutic continuum. Patient satisfaction, acceptability, quality of life, compliance, persistence and their role in developing new therapeutic modalities and compounds to optimize clinical outcomes for existing disease

\section{Dovepress}

states are major areas of interest for the journal. This journal has been accepted for indexing on PubMed Central. The manuscript management system is completely online and includes a very quick and fair peer-review system, which is all easy to use. Visit http:// www.dovepress.com/testimonials.php to read real quotes from published authors. 